\title{
Correlation of Students' Reading Comprehension and Geometry Thinking Levels
}

\author{
Yuan Ursulasari ${ }^{1}$, Susanto ${ }^{2}$, Sunardi $^{3}$, Nahrowi ${ }^{4}$ \\ 1, 2, 3,4 University of Jember, Department of Mathematics Education, \\ Jember, East Java, Indonesia
}

\begin{abstract}
:
In Mathematics, student's reading comprehension ability can be seen in their ability to change contextual Mathematics problems into Mathematics models. The ability of student changing a text which contains Mathematics problems into Mathematics models must have a connection with their ability in understanding geometry problems. Considering that rigor level, the highest level of geometry thinking ability, a deep understanding and high rigor for student to understand the text. There must be a correlation between students' reading comprehension ability and geometry thinking levels. The subjects of this research are 31 students of 10th grade in science class. They were given van Hiele Test to check their geometry thinking levels. The result of this research shows that the result of students' thinking level test and reading comprehension test has 0.466 as coefficient of correlation which means that there is a positive correlation between both abilities, the correlation is not strong.
\end{abstract}

Keywords: Reading Comprehension, Geometry Thinking Levels, van Hiele Theory, Realistic Mathematics Education.

\section{Introduction}

RME (Realistic Mathematics Education) is a constructional approach which connect Mathematics with the human truth or reality. One way to apply this constructional approach is giving contextual problems to the students. The fact that most of nowadays students are lazy to read and they don't like Mathematics problems in the form of text. And of course their ability of understanding a text may influence the result they get in doing van Hiele Test (VHT) because VHT needs good reading comprehension to be able to do it well. RME should be a fun constructional approach to connect Mathematics with reality of life. Contextual problems in the form of text should be a fun Mathematics problem for student who understand it.

The idea to find correlation of students' reading ability and geometrical thinking level came when the VHT was given to students as pretest of an experiment. Some of students directly asked what the number eleven means. For the teacher, the question is easy enough to understand but not for the students. This caused the teacher thought that their reading comprehension ability was not good enough, and this could make the students got low level of van Hiele geometrical thinking. On the other hand, the higher level of van Hiele test, the more words and sentences in the questions. So, it is no wonder why the students who had low ability of reading comprehension would get low level of van Hiele geometrical thinking. This became the reason for the researcher to proof the correlation of students' reading comprehension ability and their geometrical thinking levels. Therefore, the aim of this research is to describe the relation between reading comprehension ability and geometrical thinking.

In his journal, Velleman [2] stated that to measure the level of reading comprehension, the Dutch use the scale established by the CEFR (The Common European Framework of Reference for Languages). There are six levels of reading comprehension, they are: (1) A1 (beginner) who are able to understand very short phrase or text, words, names and basic phrase, and retell them, (2) A2 (elementary) who are able to understand a simple and short text which contain concrete familiar daily frequency problems or language about work, (3) B1 (intermediate) who are able to read factual text directly about the subjects related to his field and himself, (4) B2 (upper intermediate) who are able to read with high independence, adapt with different 
text style and quickly find the main idea of the text, (5) C1 (Advanced) who understand long text without considering if it is related to his field or not, (6) C2 (proficiency) who are able to understand and interpret all kind of written language including the abstract form, complex structured, without considering if it is a daily language or not.

For senior high school students in SMA or MA as the native speaker of Bahasa Indonesia, they should reach the highest level of reading comprehension. They should be able to understand and interpret a text. In mathematics, this ability can be tested by asking the students change the contextual mathematics problems into mathematics models.

While in van Hiele Theory, there are 5 levels of geometrical understanding. The higher the level is, the many more words or sentence in the geometry problem given. These van Hiele levels are described by van Hiele in many places. The geometrical thinking levels given by van Hiele are: Level 1 Recognition or visualization, Level 2 analysis, Level 3 order or abstraction, Level 4 deduction and Level 5 rigor. At level 1 or Recognition, students are able to recognize the name of shapes, but they think that square and rectangle are so different, they think that nothing of them are same. At level 2 or analysis, students are able to identify the characteristics of shapes, and they would say that a rectangle has four right angles. At level 3 or order, students can logically construct the shapes and construct the relation of the shapes, but they cannot operate them in Mathematics system. In this third level, a simple deduction can be followed by them, but they do not understand the proofing. At level 4 or deduction, students understand the importance of deduction, the role of postulates, theorems and proofs. In this forth level, they can write the proof by their own understanding. At level 5 which is called Rigor, students are very careful and thoroughly strict using the rules of geometry. In this highest level of geometrical thinking, the students do understand the importance of carefully works and they can make abstract deductions [9].

The van Hiele test in Usiskin modified by Rofii [9] consist of 25 multiple choice questions. There are 5 questions for each level. A student is considered complete a level if he can correctly answer at least 3 questions.

A student is considered to be in a level when he completed the previous levels. Student who completed a level without completing the previous level considered to get correct answer by guessing, so he is not considered to be in that level. Students who are not able to complete the first level is considered to be in zero level.

Blankenship [7] did an experiment toward 6 years-old. He found that there was a positive correlation between neural which function is to remember process of work and neural which work for reading comprehension and mathematics ability. But neural which deal with student's psychology had negative correlation with their reading and mathematics ability. And the neural which works for recognition has no relation with students' reading and Mathematics ability.

Magi [4] did a research about relation of self regulation to Mathematics and reading skill. The subject of the research were 775 elementary grades students. Their average age was 7.46. The result was a greater variance for complex Mathematics and reading task such as problem solving and reading comprehension when it was compared with less complex task such as calculation and word reading fluency.

Vista [1] provides different theories about the relevance of students' reading abilities to their mathematical abilities. After conducting research on 5886 students who were sitting in the 3rd to 8th grade in public schools in Victoria Australia, the results of the study show that there is no evidence of a link between students' language skills and their problem solving abilities and mathematics. The research was carried out with the assumption that all students were native speakers of English.

Isphording [8] had conducted a study on the impact of students' reading skills on the mathematical abilities of immigrant students in Europe. He studied 11.582 migrant children from 47 different countries of origin who were in 16 different destination countries. Data on migrant students is combined and examined internationally. The result showed a very strong impact of students' reading skills towards their mathematical abilities. Most of migrant students who are unfamiliar with the language in the environment or the country they had just occupied got learning difficulties because they are lack of ability in understanding the language, and of course this also affected their ability to understand the text which ultimately affected their mathematical values as well.

Mohd Salleh Abu [5] conducted research on elementary level students in Malaysia. The questions of van Hiele test at level 1, 2 and 3 were given as a pre-test and post-test. The purpose of instruction was to make the students able to learn on their own using software consisting of 3 modules with different levels. The module was created using Google 
SketchUp. The pretest results showed $10 \%$ of students were at level 0 (below level 1) and $0 \%$ of students reached level 3. And the post test results showed $0 \%$ of students at level 0 and $27.5 \%$ of students reached level 3 .

Jiri [3] conducted research on students in Czech high school. The sample studied were 215 students with details of 111 boys and 104 girls with ages ranging from 15 to 17 years old. The aim of the study was to test the Usiskin van Hiele test and compare it with the same test results in the United States. The result was $97.4 \%$ of students were able to complete level $1,91.3 \%$ of students were able to complete level 2, and $52.6 \%$ of students were able to complete level 3. And van Hiele's level of thinking could be applied in the Czech high school secondary system with results that same as in America, with emphasis on learning at level 1,2 and 3 only.

Bulut [6] conducted a study on 26 pre-service teachers of basic mathematics who were taking geometry courses. The pretest in the form of the van Hiele question was given before they began taking the class. The results showed that the maximum level of students at pretest was level 3 which was achieved by 20 students, and after learning geometry, the highest level of students was level 5 achieved by 22 students. It means that an assessment of the development of the geometrical thinking level is needed, and their lecturers must improve the way they give lectures to be more encouraging for their students to increase their level of geometrical thinking in order to have a positive impact on students in future schools.

Although in the above studies using van Hiele questions at level 1, 2 and 3 for students at those schools, researchers tried to give questions at level 4 and 5 on this research because researchers were optimistic that there would be level 4 in the research subject and it is possible that there would be students who reach the rigor level considering that one of their senior was a champion of the provincial level mathematics olympiade.

\section{Research method}

This is a correlational designed research. The research was done in Madrasah Aliyah Negeri 2 Jember, Jawa Timur, Indonesia. It is a state islamic Senior High School under the religion ministry. The research started at the beginning of November 2018 and finished at the end of December 2018. The population of this research was 31 students of a natural science class. The aim of this research is to know the correlation of students' reading comprehension and geometrical thinking levels.

The subjects of this research were students of X.IPA.5, a superior natural science class at Madrasah Aliyah Negeri 2 Jember. Their age range from 15 to 17 years old. We chose this class because after doing van Hiele Test in all ten grade classes at Madrasah Aliyah 2 Jember, the results of the test indicate that class X.IPA.5 gives the most varied results in grouping the level of students' geometric thinking. In other classes, students reached the maximum level was at level 2. But in this superior class, there was a student who reached level 3 and 2 students who reached level 4. The results of the Van Hiele test on this class of achievement can be seen in table 1.

Tabel 1: vHT resut of X.IPA.5 students

\begin{tabular}{|c|c|c|}
\hline van Hiele Level & Students & Percentage \\
\hline 0 & 6 & $19 \%$ \\
\hline 1 & 12 & $39 \%$ \\
\hline 2 & 10 & $32 \%$ \\
\hline 3 & 1 & $3 \%$ \\
\hline 4 & 2 & $6 \%$ \\
\hline 5 & 0 & $0 \%$ \\
\hline Total & 31 & $100 \%$ \\
\hline
\end{tabular}

The first collected data was the geometrical thinking levels and the reading comprehension scores of 31 students in class X.IPA.5. The level of students 'geometry thinking was measured using van Hiele Test (VHT) and the students' ability to understand the text was done by giving contextual problems as a Reading Comprehension Test (RCT). The type of data collected is quantitative data.

The instrument used to collect data in this study is the van Hiele test (VHT) which consists of 25 multiple choice questions and Reading Comprehension Test (RCT). There are 5 questions for each van Hiele level. For students at level one, he really understands the names of shapes and will not be confused even though the shape is tilted. The following is an example of the level one van Hiele question in number 4.
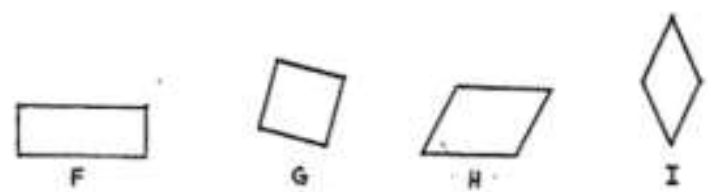

Figure 1: Figure for van Hiele Question Number 4. "Which of these are squares?
a. None of these are squares
b. G only
c. F and $\mathrm{G}$ only
d. G and I only
e. all are squares 
Students who are at level 2 already understand the characteristics of shapes. Students get questions related to the characteristics of shapes like the questions in number 6 below.

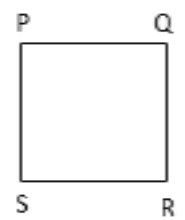

Figure 2: Figure for van Hiele Question Number 6 "PQRS is a square.

Which relationship is true in all squares?

a. PR and RS have the same length.

b. QS and PR are perpendicular.

c. PS and QR are perpendicular.

d. PS and QS have the same length.

e. Angle Q is larger than angle R"

To measure students' ability in understanding questions, tests in the form of eight contextual problems are given and students are asked to make mathematical models for these problems. Because their current subject matter is a three-variable system of linear equations, the questions given were related to that subject matter. The question bellow is a question of number 3 to test the ability of students in understanding Mathematics problem in the text form.

"A glass factory has 3 machines, they are machine $\mathrm{A}$, machine $\mathrm{B}$ and machine $\mathrm{C}$. If three of them are used, then 5,700 glasses will be produced in a week. If only machine $\mathrm{A}$ and machine $\mathrm{B}$ are used, then 3,400 glasses will be produced in a week. If only machine $A$ and machine $C$ are used, then 4,200 glasses will be produced in a week. So, how many glasses are produced by each machine every week?"

Problem number 3 above is the most correctly answered question by students, where there are 28 students who answered correctly on this number. The following is question number 6 where only 3 students correctly answer this number.

"There are two numbers where the second number is equal to six times the first number after minus one. If the first number is squared then added by three, the result is also the same as the second number. Each of the two numbers are ..."

Because students and teachers discussed about three variables linear equation system for several days before the research, of course for question number 3 there were many students who answered correctly because the problem model had been recognized by the students. Problem number 6 is deliberately given to test students' understanding of what they read. Students might suspect that the mathematical model for question number 6 is also a system of three-variable linear equations, but for students who really understand what they are reading, he will write a mathematical model for number 6 in the form of a two-variable system of linear quadratic equations.

Because the test of problem solving ability given to students is to change the story problem into a mathematical model with the theme of a three variables linear equation system, then each question students are challenged to make three equations combined into a system of equations. Every time student gives a right mathematical equation for the Mathematics model, the value given is one. Because each number of the equations formed is three, the score of each number range from 0 to 3 . Correlation of data consisting students' geometry level and score of Reading Comprehension Ability were evaluated using SPSS.

\section{Result and discussion}

\subsection{Result}

Table 2 percentage of students' right answer on van Hiele

\begin{tabular}{|c|c|c|c|c|c|c|c|c|c|c|c|c|}
\hline \multirow{3}{*}{$\begin{array}{c}\begin{array}{c}\text { Question } \\
\text { number }\end{array} \\
\mathbf{1} \\
\end{array}$} & \multicolumn{10}{|c|}{$\begin{array}{c}\begin{array}{c}\text { Number of students who are correctly answer at the } \\
\text { level }\end{array} \\
\end{array}$} & \multirow{3}{*}{\begin{tabular}{|c|} 
TOTAL \\
24 \\
\end{tabular}} & \multirow{3}{*}{\begin{tabular}{|c|} 
Percentage \\
$80 \%$ \\
\end{tabular}} \\
\hline & \multicolumn{2}{|c|}{0} & \multicolumn{2}{|c|}{1} & \multicolumn{2}{|c|}{2} & \multicolumn{2}{|c|}{\begin{tabular}{|l|}
3 \\
\end{tabular}} & \multicolumn{2}{|c|}{4} & & \\
\hline & 2 & $33 \%$ & 10 & $83 \%$ & 9 & $90 \%$ & 1 & $100 \%$ & 2 & $100 \%$ & & \\
\hline 2 & 4 & $67 \%$ & 10 & $83 \%$ & 10 & $100 \%$ & 1 & $100 \%$ & 2 & $100 \%$ & \begin{tabular}{|l|}
27 \\
\end{tabular} & $90 \%$ \\
\hline 3 & 3 & $50 \%$ & 9 & $75 \%$ & 9 & $90 \%$ & 1 & $100 \%$ & 2 & $100 \%$ & 24 & $80 \%$ \\
\hline 4 & 1 & $17 \%$ & 7 & $58 \%$ & 4 & $40 \%$ & 1 & $100 \%$ & 2 & $100 \%$ & 15 & $50 \%$ \\
\hline 5 & 1 & $17 \%$ & 4 & $33 \%$ & 5 & $50 \%$ & 0 & $0 \%$ & 0 & $0 \%$ & 10 & $33 \%$ \\
\hline 6 & 2 & $33 \%$ & 1 & $8 \%$ & 4 & $40 \%$ & 0 & $0 \%$ & 1 & $50 \%$ & 8 & $27 \%$ \\
\hline 7 & 3 & $50 \%$ & 7 & $58 \%$ & 10 & $100 \%$ & 1 & $100 \%$ & 2 & $100 \%$ & 23 & $77 \%$ \\
\hline 8 & 4 & $67 \%$ & 3 & $25 \%$ & 3 & $30 \%$ & 0 & $0 \%$ & 2 & $100 \%$ & 12 & $40 \%$ \\
\hline 9 & 3 & $50 \%$ & 3 & $25 \%$ & 9 & $90 \%$ & 1 & $100 \%$ & 2 & $100 \%$ & 18 & $60 \%$ \\
\hline 10 & 2 & $33 \%$ & 3 & $25 \%$ & 7 & $70 \%$ & 1 & $100 \%$ & 2 & $100 \%$ & 15 & $50 \%$ \\
\hline 11 & 3 & $50 \%$ & 2 & $17 \%$ & 2 & $20 \%$ & 1 & $100 \%$ & 2 & $100 \%$ & 10 & $33 \%$ \\
\hline 12 & 1 & $17 \%$ & 5 & $42 \%$ & 1 & $10 \%$ & 1 & $100 \%$ & 0 & $0 \%$ & 8 & $27 \%$ \\
\hline 13 & 3 & $50 \%$ & 3 & $25 \%$ & 3 & $30 \%$ & 0 & $0 \%$ & 2 & $100 \%$ & 11 & $37 \%$ \\
\hline 14 & 0 & $0 \%$ & 0 & $0 \%$ & 1 & $10 \%$ & 0 & $0 \%$ & 0 & $0 \%$ & 1 & $3 \%$ \\
\hline 15 & 3 & $50 \%$ & 3 & $25 \%$ & 5 & $50 \%$ & 1 & $100 \%$ & 2 & $100 \%$ & 14 & $47 \%$ \\
\hline 16 & 1 & $17 \%$ & 1 & $8 \%$ & 3 & $30 \%$ & 1 & $100 \%$ & 2 & $100 \%$ & 8 & $27 \%$ \\
\hline 17 & 2 & $33 \%$ & 4 & $33 \%$ & 3 & $30 \%$ & 1 & $100 \%$ & 2 & $100 \%$ & 12 & $40 \%$ \\
\hline 18 & 2 & $33 \%$ & 0 & $0 \%$ & 0 & $0 \%$ & 0 & $0 \%$ & 0 & $0 \%$ & 2 & $7 \%$ \\
\hline 19 & 0 & $0 \%$ & 2 & $17 \%$ & 1 & $10 \%$ & 0 & $0 \%$ & 2 & $100 \%$ & 5 & $17 \%$ \\
\hline 20 & 3 & $50 \%$ & 5 & $42 \%$ & 2 & $20 \%$ & 0 & $0 \%$ & 0 & $0 \%$ & 10 & $33 \%$ \\
\hline $\begin{array}{c}\text { Total } \\
\text { Students }\end{array}$ & stuc & $\begin{array}{l}6 \\
\text { dents }\end{array}$ & $\begin{array}{r}1 \\
\text { stuo }\end{array}$ & 12 & $\begin{array}{r}1 \\
\text { stud }\end{array}$ & $\begin{array}{l}10 \\
\text { dents }\end{array}$ & & $\begin{array}{c}1 \\
\text { dents }\end{array}$ & & $\begin{array}{l}2 \\
\text { dents }\end{array}$ & & tudents \\
\hline
\end{tabular}

From table 2, it can be seen that the least correctly answered question by students is van Hiele question number 14 . The given problem is as follows:

"Which is true?

a. All properties of rectangles are properties of all squares.

b. All properties of squares are properties of all rectangle. 
c. All properties of rectangles are properties of all parallelograms.

d. All properties of squares are properties of all parallelograms.

e. None of (a) - (d) is true."

Things that might cause only one student who correctly answer question number 4 is the level of students difficulty in understand the text. The students may not understand the characteristics of shapes and they are confuse to catch what the question means.

Next, the least correctly answered question by the students is question number 18. If we look at the question, we will understand that students who answer incorrectly for question number 18 have difficulty in understanding the series of words or the combination of words in the question. Here is the question of van Hiele number 18.

"Here are two statements.

I : If a figure is a rectangle, then its diagonals bisect each other.

II: If the diagonals of a figure bisect each other, the figure is a rectangle.

Which is correct?

a. To prove I is true, it is enough to prove that II is true.

b. To prove II is true, it is enough to prove that I is true.

c. To prove II is true, it is enough to find one rectangle whose diagonals bisect each other.

d. To prove II is false, it is enough to find one nonrectangle whose diagonals bisect each other.

e. None of $(a)-(d)$ is true."

The series of words in van Hiele number 19 is also more than the questions at other levels have. This could be the cause of the low level of student reading comprehension towards the van Hiele level. Next, we test the correlation of the relationship between the two types of student abilities using SPSS.

Before determining that the VHT and RCT results were tested by Pearson Correlation, the normality of the data was checked using SPSS. Asymp Value. Sig. (2-tailed) for VHT is 0.666 and for RCT is 0.089 which means that both data from the test results are normally distributed.

Table 3 Result of VHT and RCT

\begin{tabular}{cccccc}
\hline Student & VHT & RCT & Student & VHT & RCT \\
\hline 1 & 2 & 54,2 & 17 & 2 & 50 \\
\hline & & & & & 41, \\
2 & 0 & 33,3 & 18 & 1 & 7 \\
\hline 3 & 1 & 54,2 & 19 & 4 & 45, \\
\hline
\end{tabular}

\begin{tabular}{|c|c|c|c|c|c|}
\hline 4 & 2 & 50 & 20 & 0 & $\frac{8}{25}$ \\
\hline & & & & & 58, \\
\hline 5 & 1 & 37,5 & 21 & 1 & 3 \\
\hline \multirow[t]{2}{*}{6} & 2 & 41,7 & 22 & 0 & 50 \\
\hline & & & & & 54, \\
\hline \multirow[t]{2}{*}{7} & 1 & 41,7 & 23 & 2 & 2 \\
\hline & & & & & 41, \\
\hline \multirow[t]{2}{*}{8} & 2 & 62,5 & 24 & 1 & 7 \\
\hline & & & & & 45 \\
\hline \multirow[t]{2}{*}{9} & 0 & 29,2 & 25 & 2 & 8 \\
\hline & & & & & 29 , \\
\hline \multirow[t]{2}{*}{10} & 1 & 37,5 & 26 & 3 & 2 \\
\hline & & & & & 41, \\
\hline 11 & 4 & 54,2 & 27 & 1 & 7 \\
\hline \multirow[t]{2}{*}{12} & 2 & 33,3 & 28 & 2 & 50 \\
\hline & & & & & 33 , \\
\hline \multirow[t]{2}{*}{13} & 1 & 16,7 & 29 & 1 & 3 \\
\hline & & & & & 37, \\
\hline \multirow[t]{2}{*}{14} & 0 & 0 & 30 & 2 & 5 \\
\hline & & & & & 45 , \\
\hline 15 & 0 & 37,5 & 31 & 1 & 8 \\
\hline 16 & 1 & 41,7 & & & \\
\hline
\end{tabular}

The results of the correlation test using SPSS showed the significance value between the Geometry Thinking Level (VanHieleTest) and the Reading Comprehension Ability (ReadingComprehension) was $0.004<0.05$. This means that there is a significant correlation between the level of students' geometric thinking and their ability to understand the text. Correlation coefficient $r=0.466$ is positive, which means that the higher the ability of students to understand the text, the higher the level of geometry thinking will be. However, the correlation of both students' abilities is low or not too strong because the number of correlation coefficient $r$ is not greater than 0.5 .

\subsection{Discussion}

From the results of the study, it can be said that students who did not complete at level 1 felt confused when a shape was tilted. They thought that a tilted square is not a square, so is a tilted parallelogram. This can be seen from the research data that students who did not complete at level one answered the least correctly in numbers 4 and 5 . They even had difficulty distinguishing between square and rectangle. At number 1, many of them chose $\mathrm{D}$ as an answer, which means they think that a rectangle (persegi panjang) is a long square (persegi yang panjang). This is a risk when two different shapes have similar names in Indonesian. This wrong thought are caused by their tending to see the 
meaning of the name, not the characteristics of the shapes. In addition, the questions on level one contain fewer words than the questions at the next levels. Questions at level 1 test whether students really know the names of the shapes they see. If it is associated with the reading comprehension level, the questions at level 1 are at level A1 of reading comprehension level.

Students who are unable to solve questions at level 2 are at most wrong in answering question number 6 . This means that they do not understand the characteristics of a square. Words that they might not understand at number 6 are square, perpendicular and angle. They might also not understand that the square diagonal is longer than the square side. The second smallest percentage after number 6 is numbers 8,9 and 10 where there are only $25 \%$ of students or 3 of 12 students who answer correctly. For number 8 , it is possible for students to think if it is a parallelogram or a kite even though it had already been written that it is a rhombus. Students believe more in what they see than what he reads. When working on number 9, students may think that the triangle is an equilateral triangle even though what is written on the question is an isosceles triangle. The incomprehension of the shapes' names in detail can lead to students misunderstand in imagining the shapes and the shapes' characteristics. Likewise in question number 10, when students do not understand that all the radius of a circle have the same length, he cannot guess that PSQR is a kite shape. Students who cannot distinguish rhombus, kite and parallelogram will be wrong in giving answers.

Students who could not complete level 3 answer the most incorrectly at number 12 and 14. Students who do not know the full characteristics of shapes would answer these questions incorrectly, especially if students only imagine the shapes' properties and relate them to the problem. If the student who understands the characteristics of shapes writes the characteristics on the paper then compares them, he will be correct in answering. So the difficulty of the question in this number is to imagine what they read and associate it with the answer choices. Questions like this are at the highest level of reading comprehension ability, namely level $\mathrm{C} 2$.

From Blankenship [7] research, it can be said that students' reading abilities and mathematical abilities are connected in one type of the same nerve, namely nerves to remember processes. This is what might cause a positive relationship between RCT and VHT students. But Blankenship also states that nerves associated with the ability to recognize objects are not correlated to students' reading and mathematical abilities, and this can be the reason why the correlation coefficient is only 0.466 , which means students' ability to recognize shapes is not too related to students' ability to understand the characteristics of shapes.

Magi [4] also states that the more complex the mathematical material is given, the less related it is to the reading comprehension ability. And this is also supported by the Vista study [1] which states that there is no linkage between reading ability and problem solving abilities and students' mathematical abilities.

Contrary, Isphording [8] stated that the students' reading comprehension greatly influences the mathematical value of migrant children because they have to learn in a language that is not a language from their home region. Therefore, the researcher concludes that language skills at high levels have a weak correlation with high mathematical abilities.

Geometry contains terms that are not usually used by students. Students may have gotten geometric terms at the previous level of learning but they may have forgotten or indeed they did not understand it from the beginning. Students studying in high school use their own language to study with their friends and their teacher because they are not immigrant students, of course, they should master the language used in school. If we include their level of ability to understand the text, they are naturally at level $\mathrm{C} 1$ or C2 where students are able to interpret the text he reads into mathematical models. However, the lack of mastery of geometric terms may resist their geometric abilities to a higher level of geometrical thinking.

\section{References}

[1] Vista, A., "The role of reading comprehension in maths achievement growth, Investigating the magnitude and mechanism of the mediating effect on maths achievement in Australian classrooms". International Journal of Educational Reserach, 62, pp. 21-35, 2013.

[2] Velleman, E., \& Geest, T.,V., D., "Online test tool to determine the CEFR reading comprehension level of text". Procedia Computer Science, 27, pp. 350-358, 2014.

[3] Jiri, H., \& Vojkůvková, I., "The van Hiele Levels at Czech Secondary Schools". Social and Behavioral Science, 171, pp. 912-918, 2015. 
[4] Magi, K., Mannamaa M., \& Kikas E., "Profiles of self-regulation in elementary grades, Relations to math and reading skills". Learning and Individual Differences, 51, pp. 37-48, 2016.

[5] Abu, M., S., Ali M., B., \& Hock T., T., "Assisting primary school children to progress through their van Hiele's levels of geometry thinking using google SketchUp". International educational technology conference, 64, pp. 7584, 2012.

[6] Bulut, N., \& Bulut M., "Development of preservice elementary mathematics teachers' geometric thinking Levels through An Undergraduate Geometry Course". Social and Behavioral Sciences, 46, pp. 760-763, 2012.

[7] Blankenship, T., L., Kayla, K., Calkins S., D., \& Bell M., A., "Behavioral performance and neural areas associated with memory processes contribute to math and reading achievement in 6-year-old children". Cognitive Development, 2017.

[8] Isphording, I., E., Piopiunik M., \& Planas N., R., "Speaking in number, The effect of Reading: performance on math performance among imigrants". Economic Letters, 139, 52-56, 2016.

[9] Rofii A., Sunardi, Irvan M., "Characteristics of Students' Metacognition Process At Informal Deduction Thinking Level in Geometry Problems," Int. J. Emerg. Math. Educ, 2(1), 89104, 2018.

\section{Author 1 Profile}

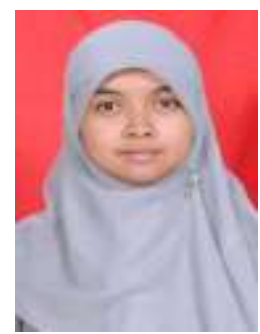

Yuan Ursulasari received the bacelor degrees in Mathematics and Science Faculty of Jember University in 2001 and 2006, respectively. During 2006 until now, she has been a Mathematics teacher at MAN 2 Jember, an Islamic Senior High School under Ministry of Religion of Indonesia. During 2017 until now, she has also been a student of Mathematics Education Magister Program of Jember University.

\section{Author 2 Profile}

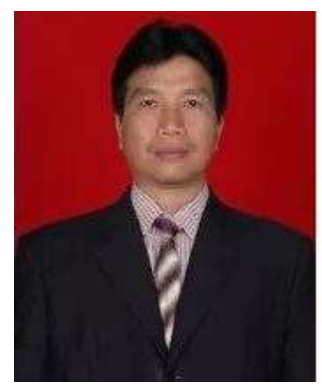

Susanto received the bacelor degrees in Jember University and Master degrees in Malang University, respectively. He received his doctoral degree at Surabaya University, East Java, Indonesia. He is now a lecturer at Mathematics Education Department of Educational Faculty of Jember University, East Java, Indonesia.

\section{Author 3 Profile}

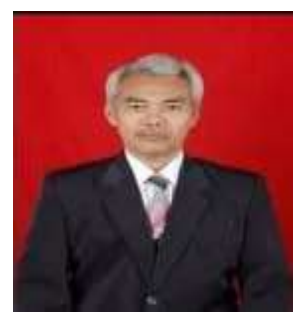

Sunardi received the bacelor and Master degrees in IKIP Malang, respectively. He received his doctoral degree at Surabaya University, East Java, Indonesia. He is now a profesor who teaches at Mathematics Education Department of Educational Faculty of Jember University, East Java, Indonesia.

\section{Author 4 Profile}

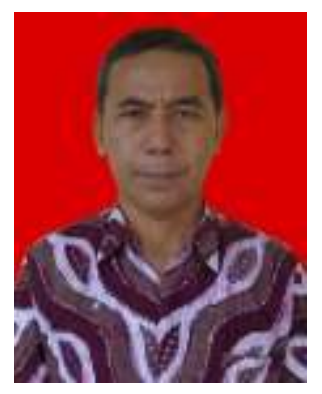

Nahrowi received the Bacelor degrees in IKIP Malang, in 1982 and 1986, respectively. During 1989-2015, he has been a Mathematics Teacher at SMAN 4 Jember, a state public senior high school. $\mathrm{He}$ is now a headmaster of SMAN Rambipuji Jember, another state public senior high school in Jember, East Jawa, Indonesia. 